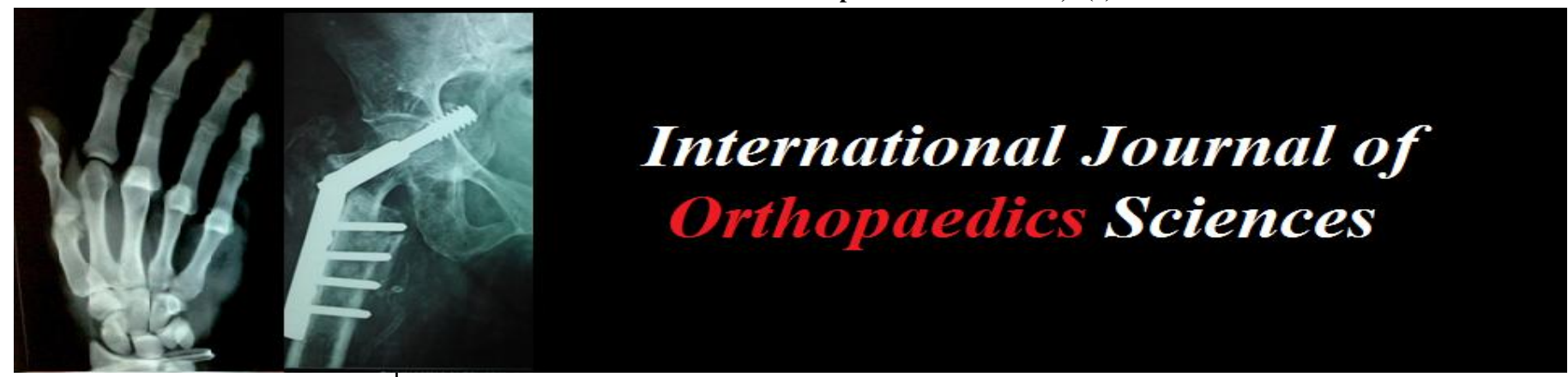

ISSN: $2395-1958$

IJOS 2018; 4(1): 590-598

(C) 2018 IJOS

www.orthopaper.com

Received: 05-11-2017

Accepted: 06-12-2017

Vellanki Sarath

Associate Professor,

Katuri Medical College \&

Hospital, A Unit of Vignan

Education Chinna Kondrupadu

Guntur, Andhra Pradesh

India

A Srinivasa Rao

Professor and HOD,

Katuri Medical College \&

Hospital, A Unit of Vignan

Education Chinna Kondrupadu

Guntur, Andhra Pradesh

India

Shaik Akbar Basha

Post Graduate,

Katuri Medical College \&

Hospital, A Unit of Vignan

Education Chinna Kondrupadu

Guntur, Andhra Pradesh

India

\section{A study of uncemented total hip replacement in various hip disorders}

\author{
Vellanki Sarath, A Srinivasa Rao and Shaik Akbar Basha
}

DOI: https://doi.org/10.22271/ortho.2018.v4.i1i.85

\section{Abstract}

Background: Osteoarthritis (OA) is a major cause of disability among elderly population. It is a major cause of a burden on the health system and its incidence and prevalence continues to rise with a rapidly increasing aging population.

Total hip replacement is considered one of the most important and successful intervention in the recent era. The study aims to determine the functional outcome and the complications associated with uncemented total hip replacement using modular prosthesis. In this study 32 cases with osteoarthritis of hip joint were treated by uncemented total hip replacement at Katuri medical college and hospital, China kondrupadu, Guntur between June 2015 to November 2016 were included. The functional outcome is assessed and compared with other studies. The aim of procedure is to assess the functional outcome of uncemented total hip replacement.

Materials and Methods: Our study is prospective study of clinical and radiological analysis of uncemented total hip arthroplasties performed for various hip disorders.

All patient data and clinical history were noted with reference to pain, range of motion, gait, activities or function (Harris Hip Score).

Cementless acetabular components, cementless femoral components are used in this study.

Results: All 32 patients in the present study returned for clinical and radiological examinations subsequently. Patients were reviewed after 6 weeks, 3 months, 6 months and 1 year post operatively.

The age ranges from 32- 60 years with mean age of 48.31 years. Most of the cases are between the age group of $51-60$ years constituting $46.88 \%$ of study population. Of the 32 cases, male patients 22 constituting $68.75 \%$ and the rest 10 are female patients constituting $31.25 \%$ of the cases.

Conclusions: Our study supports the usge uncemented THR in osteoarthritis in both young and elderly. The current trend, research and advent of new implants support uncemented THR in patients suffering from this crippling hip arthritis and avascular necrosis.

Keywords: Uncemented total hip arthoplasty, THR, Acetabular cup, femoral component

\section{Introduction}

Osteoarthritis (OA) is a major cause of disability among elderly population. It is a major cause of burden on the health system and its incidence and prevalence continues to rise with a rapidly increasing aging population. OA occurs due to an interaction between certain systemic and local factors which are unique for each joint. Hip OA can be classified as idiopathic and secondary. Total hip replacement is considered one of the most important and successful intervention in the recent era. Since total hip replacement was introduced, there has been a steady improvement in the technology associated with it, leading to better functional outcome implant survivorship. The development of circumferentially coated uncemented implants which allow bone to grow in to or on to the prosthesis has led to improved implant survival rate and supports their growing use. The advantages of cementless femoral components include a reduced risk of cement-related cardiovascular and thromboembolic complications, the possibility of biological fixation, the minimization of stress shielding of the proximal femur and potential of extended implant survival.

The study aims to determine the functional outcome and the complications associated with uncemented total hip replacement using modular prosthesis. In this study 32 cases with osteoarthritis of hip joint were treated by uncemented total hip replacement at Katuri medical college and hospital, Chinakondrupadu, Guntur between June 2015 to November 2016 were included. The functional outcome is assessed and compared with other studies. The aim of the procedure is to assess the functional outcome of uncemented total hip replacement.
Correspondence

Vellanki Sarath

Associate Professor,

Katuri Medical College \&

Hospital, A Unit of Vignan

Education Chinna Kondrupadu

Guntur, Andhra Pradesh

India 


\section{Aims and Objectives of the Study}

To assess the clinical and radiological outcome of uncemented total hip replacement in osteoarthritis of hip.

To assess the clinical outcome using harris hip score comparing pre-operative scores with post-operative scores.

To evaluate functional improvement in terms of pain relief, mobility and range of movements.

To evaluate radiological outcome at the end of 3 months and 1 year follow up.

To evaluate the post-operative complications.

\section{Materials and Methods}

Materials: Cement less acetabular components

1. Tridant acetabular shell with poly or alumina ceramic bearing (stryker).

2. Duralocacetabular shell with poly or ceramic bearings (Depuy).

3. Delta motion acetabular mobile bearing system (Depuy).

4. Trilogy acetabular cup cluster holed or multiholed shell with standard or highly crosslinked poly liners (Zimmer).

5. Biolox delta acetabular cup with ceramic bearing (Exatech).

6. Verilastacetabularcup with ceramic bearing (Smith and Nephew).

\section{Cement less Femoral Components}

1. Acolade stems with tapered wedge stem and proximal body hydroxyl apatite \& plasma spray coating (Stryker).

2. Corailcementless femoral stem- hydroxylapetite coated collarless stem (Depuy).

3. Acumatch stem with hydroxyapetite \& plasma spray coating (Exatech).

4. $\mathrm{M} / \mathrm{L}$ taper femoral stem (Zimmer).

5. Short modular femoral stems (Smith \& Nephew).

\section{Methods}

Study type: Our study is a prospective study of clinical and radiological analysis of uncemented total hip arthroplasties performed for various hip disorders.

Study area: study was carried out in orthopaedic department of Katuri medical college and hospital, Chinakondrupadu, Guntur from June 2015 to November 2016.

Study population: Patients diagnosed with osteoarthritis of hip joint with stage III and IV, who underwent uncemented total hip replacement are included in our study. All the patients were explained about the procedure, necessity for follow up and written consent was taken. 35 patients in total who underwent uncemented total hip arthoplasty for osteoarthritis during the period were eligible for the study. 3 patients who were not available for regular follow ups were excluded from the study. 32 patients who were available for minimum of 1 year follow up were included in our study. Total of 32 arthoplasties were performed in 32 patients. These were done between June 2015 and November 2016.

\section{Inclusion criteria}

Patients with significant disabling hip pain and moderate to severe functional limitation of activities of daily living due to osteoarthritis of the hip joint with any of the etiologies.

Patients having a minimum period of 12 months of follow up were included in the study.

\section{Exclusion criteria}

Total hip arthroplasties performed as revision for patients of post-operative hemiarthroplasties or previous THRs were excluded.

All patients' data and clinical history were noted with reference to pain, range of motion, gait, activities or function (Harris Hip Score), pre operatively and at scheduled follow up visits.

\section{Pre-operative planning}

Preoperative planning enables the surgeon to prepare for the case and anticipate situations that may arise during surgery. A thorough preoperative plan incorporates elements from the patient's history, physical examination and radiographic analysis. All the patients were evaluated clinically based Harris hip score. Patients were also evaluated preoperatively for remote source of infection by taking throat swab and urine culture.

- Clinical assessment in terms of range of motion, pain, restriction of distance walked and restriction of carrying out daily activities.

- Associated medical problems: Hypertension, diabetes mellitus, coronary heart disease, coronary artery disease, past history of thromboembolism, COPD, history of recent throat, urinary and other infections were evaluated.

- Adequate compatible blood was reserved before surgery.

\section{Pre-operative Radiographic Templating}

The goals include

- Determine preoperative leg length discrepancy.

- Assess acetabular component size and placement.

- Determine femoral component size, position and fit.

- Assess femoral offset.

\section{Acetabular Cup Sizing and Position}

Most sizing predictions are made on the AP radiograph of the hip. The optimal position for the acetabular component and size was determined by using template overlays. The acetabular teardrop was referenced as the inferior margin of the acetabular reconstruction. The goal of acetabular fixation was to maximize bone contact. Once this was determined the centre of rotation of the bearing surface marked.

\section{Femoral Component Selection}

The femoral component template size that will fit the proximal femur and equalize the leg lengths was selected. The femoral component should be in line with the long axis of the femur and the neck resection line drawn at the point where the selected stem provides the desired amount of leg length. The vertical distance between the planned centre of rotation of the acetabular component and the centre of rotation of the femoral head constitutes the distance the leg length will be adjusted. The level of neck osteotomy depends on the stem size and the desired leg length. To properly position the template on the lateral radiograph the distance between the tip of the greater trochanter and the lateral shoulder of the prosthesis is estimated. The stem size that is chosen in the AP plane also should fit in the lateral plane. The lateral radiograph of a properly sized tapered implant will typically exhibit three- point fixation.

\section{Offset Requirements}

Through Templating and intra operative trial we determined which option restores proper offset by matching the cup's centre of rotation with the desired head centre of rotation. 


\section{Anaesthesia}

Patients received epidural and general anaesthesia or spinal and epidural anaesthesia as per anaesthetist evaluation and patients general condition.

\section{Surgical Approach}

Posterolateral approach by Gibson and Moore's had been used as per preference of the operating surgeon.

\section{Post-Operative Management}

Both the limbs were kept in abduction with a pillow in between the legs. Post operative analgesia was adequately given in the form of epidural analgesia for minimum of 48 hours and maximum of 72 hours. Intravenous antibiotics were used for 3 days, and then converted to oral antibiotics for another 3 days.

Heparin (LMW) was subcutaneously given for prevention of thromboembolic events for 7 days followed by 5 to 6 weeks course of ecosprin or total 6 week course of LMWH. Prophylaxis against heterotopic bone formation was not routinely used.

Patients were encouraged to sit up in the bed from the first post operative day. Active abduction strengthening exercises were begun from the second post operative day under the supervision of our physiotherapist. Patients start weight bearing from day one as tolerated, followed by early ambulation on day 2 with walker support. Mandatory 2 week walker support while walking was advised. From 2-6 weeks patients are encouraged to shift over to elbow crutch or tripod stick support as tolerated. Patients are allowed to walk without support by end of 6 weeks.

\section{Follow Up Evaluation}

Clinical assessment was done using Harris Hip Score pre operative and post operative at 6 weeks, 3, 6 and 12 months follow up and points were apportioned accordingly.

Radiographs were also analyzed with reference to signs of loosening at end of 3 months and 1 year.

\section{Radiological Analysis}

Post op $\mathrm{x}$ rays are evaluated for

1) Position of the cup: normal, horizontal, vertical, very deep, very superficial, anteverted, retroverted

2) Position of the stem: normal, varus, valgus

\section{Observations and Results}

All 32 patients in the present study returned for clinical and radiological examinations subsequently. Patients were reviewed after six weeks, three months, six months and one year post operatively. Radiographs were reviewed at end of 3 months and 1year. Observations in the form of tables, pie charts and bar diagrams are furnished.

\section{Age Distribution}

The age ranges from 32-60 years with mean age of 48.31years. Most of the cases are between the age group of 51 to 60 years constituting $46.88 \%$ of study population

\section{Sex Distribution of Study Patients}

Of the 32 cases included in the study majority are male patients. 22 patients are male constituting $68.75 \%$ of cases and the rest 10 are female patients constituting $31.25 \%$ of the cases
Age and Sex

\begin{tabular}{|c|c|c|c|}
\hline & Male & Female & Total \\
\hline $30-40$ & 7 & 4 & 11 \\
\hline $41-50$ & 5 & 1 & 6 \\
\hline $51-60$ & 10 & 5 & 15 \\
\hline Total & 22 & 10 & 32 \\
\hline
\end{tabular}

Etiology Identified Among Study Patients:

\section{ETIOLOGY}

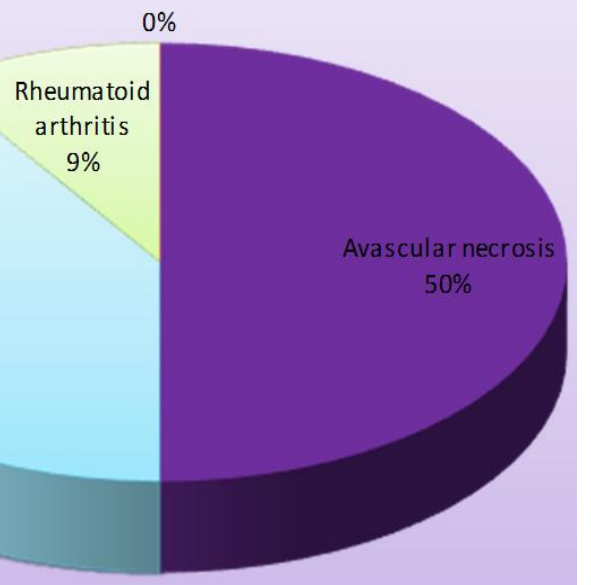

- Idiopathic osteonecrosis was most common etiology accounting for $50 \%$ of cases

- $41 \%$ of cases are due to primary osteoarthritis

- $\quad 9 \%$ of cases are due to rheumatoid arthritis.

\section{Etiology in the study group}

\begin{tabular}{|c|c|c|}
\hline Etiology & No. of cases (N) & Percentage (\%) \\
\hline Avascular necrosis & 16 & $50 \%$ \\
\hline Primary osteoarthritis & 13 & $41 \%$ \\
\hline Rheumatoid arthritis & 3 & $9 \%$ \\
\hline
\end{tabular}

\section{Side Involved}

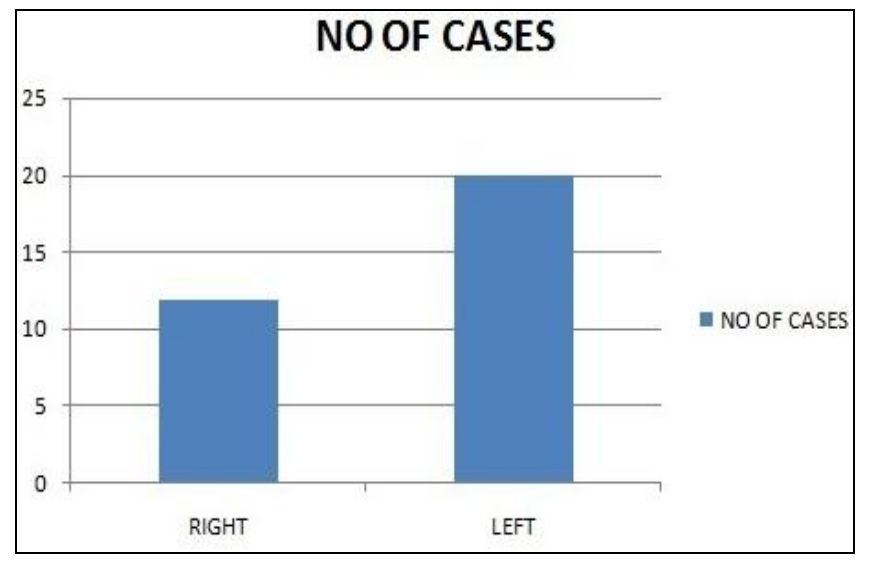

\section{Side Involved}

\begin{tabular}{|c|c|c|}
\hline Side Involved & No. Of Cases & Percentage \\
\hline RIGHT & 12 & $37.5 \%$ \\
\hline LEFT & 20 & $62.5 \%$ \\
\hline
\end{tabular}


Harris Hip Score at 1yr follow up

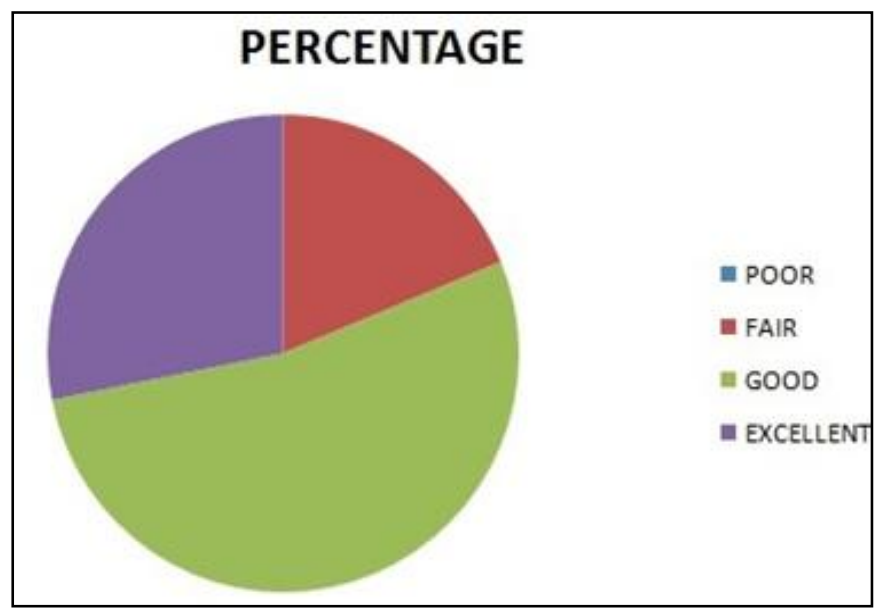

Harris Hip Score at 1yr follow up

\begin{tabular}{|c|c|c|}
\hline Outcome & Number (N) & Percentage (\%) \\
\hline Poor & 0 & $0 \%$ \\
\hline Fair & 6 & $18.75 \%$ \\
\hline Good & 17 & $53.13 \%$ \\
\hline Excellent & 9 & $28.13 \%$ \\
\hline
\end{tabular}

Range of Improvement in Harris Hip Score at Every Follow Up

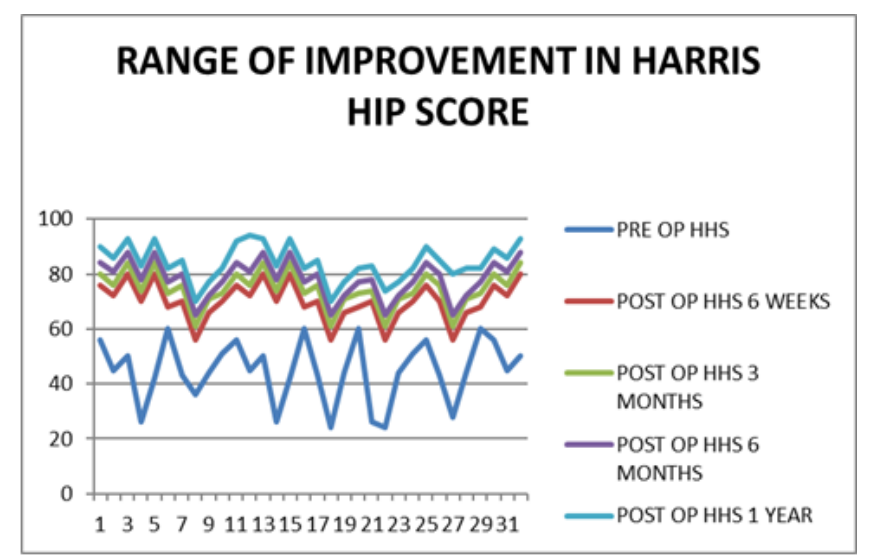

\section{Clinical Outcome}

The average pre-operative Harris hip score (HHS) was 44.69. The Harris hip score at most recent follow up (1yr) was 84.2. The result was excellent in 9 patients, Good in 17 patients, fair in 6 patients. Mean HHS at each follow up visit was compared with pre-operative HHS using Paired T test and $\mathrm{p}$ values were calculated. $\mathrm{P}$ value was found to be significant with each comparison.

\begin{tabular}{|c|c|c|c|c|c|}
\hline \multicolumn{7}{|c|}{ Statistics Of Pre Op \& Post Op HHS Comparision } \\
\hline & Preophhs & Postophhs 6 weeks & Postophhs 3 months & Postophhs 6 months & Postophhs1year \\
\hline Mean & 44.688 & 70.000 & 74.500 & 78.219 & 84.219 \\
\hline Std. Deviation & 11.2119 & 7.0023 & 6.6672 & 6.9734 & 6.6271 \\
\hline Minimum & 24.0 & 56.0 & 61.0 & 65.0 & 70.0 \\
\hline Maximum & 60.0 & 80.0 & 84.0 & 88.0 & 94.0 \\
\hline
\end{tabular}

\section{Mean Pain Scor}

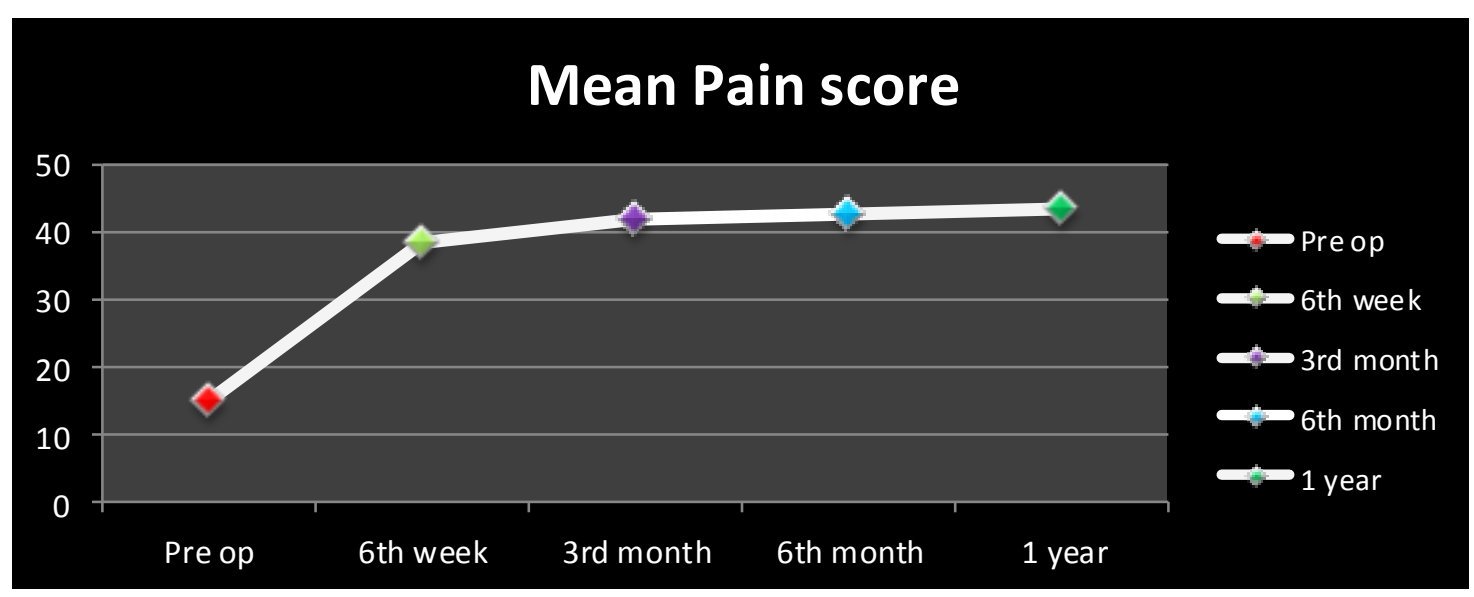

Pain score in Harris hip score

\section{Limp}

None of the patients had significant limp at final follow up.

\section{Satisfaction:}

All the patients were satisfied with the outcome of the total hip arthroplasty except one of the patients who had infection. All the patients considered hip to have better function than prior to surgery.

\section{Radiological Outcome}

Femoral stem

Radiographic evidence did not reveal any signs of loosening. At last follow up, none of the radiographs showed any significant ( $2 \mathrm{~mm}$ or more) radiolucency. The femoral stem was aligned in neutral in 26 hips. 4 stems were in mild valgus and 2 were in mild varus positions. No patient had complained of pain in the thigh. 


\section{Stem alignment}

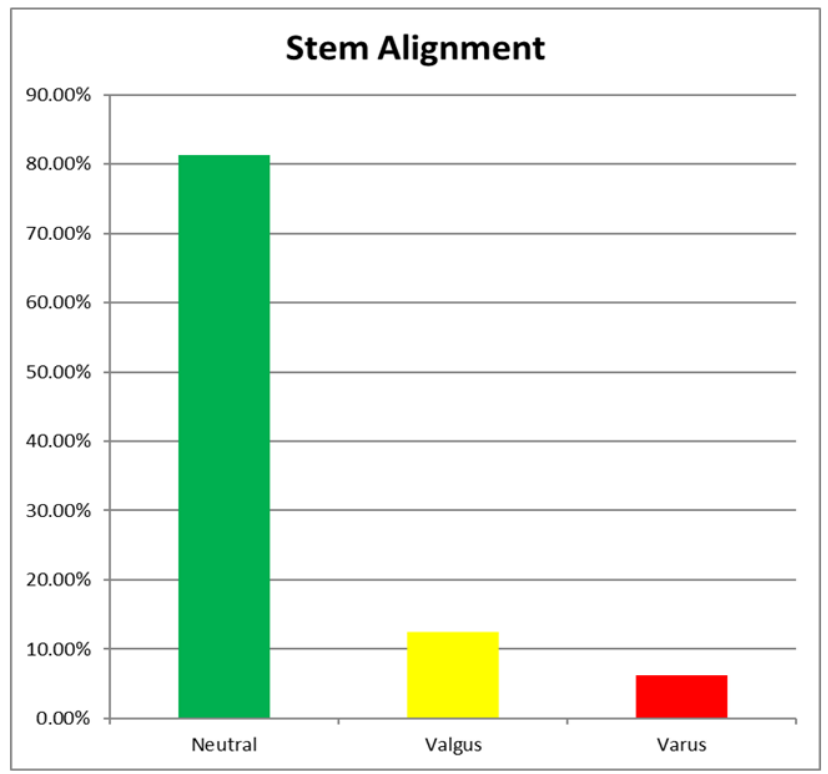

\section{Acetabular cup}

All acetabular components were stable when seen at final follow up. Average acetabular inclination was $50^{\circ}$. No cup had broken screws.

Pre \& Post OP Imaging of Selected Cases

Case 3: 37/F Avascular Necrosis of Left Hip
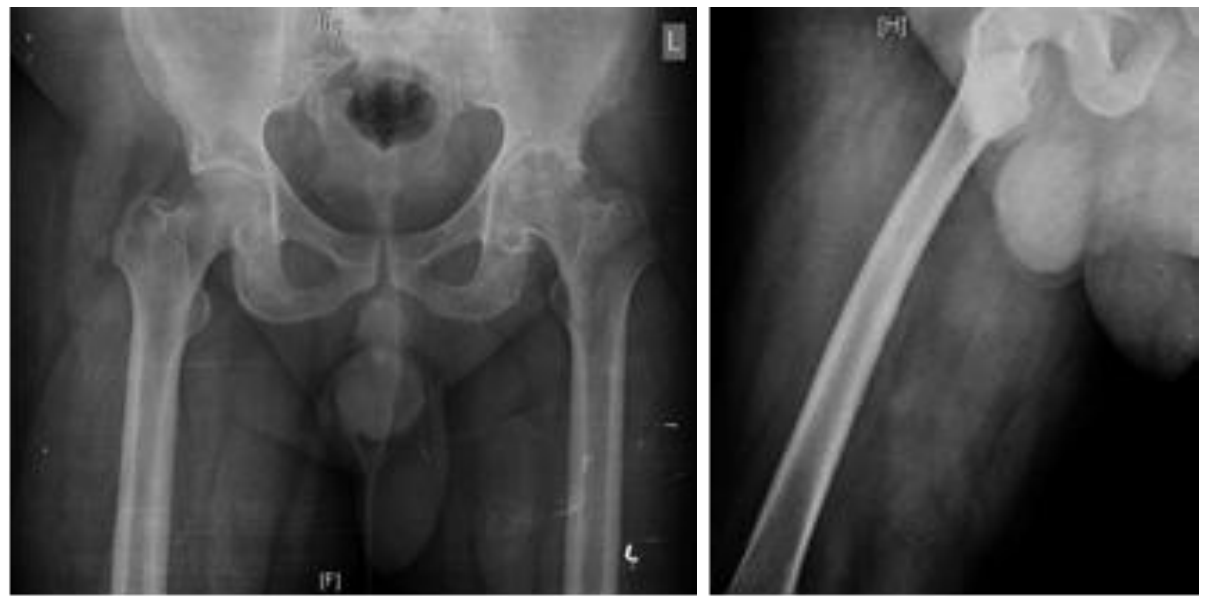

Pre op

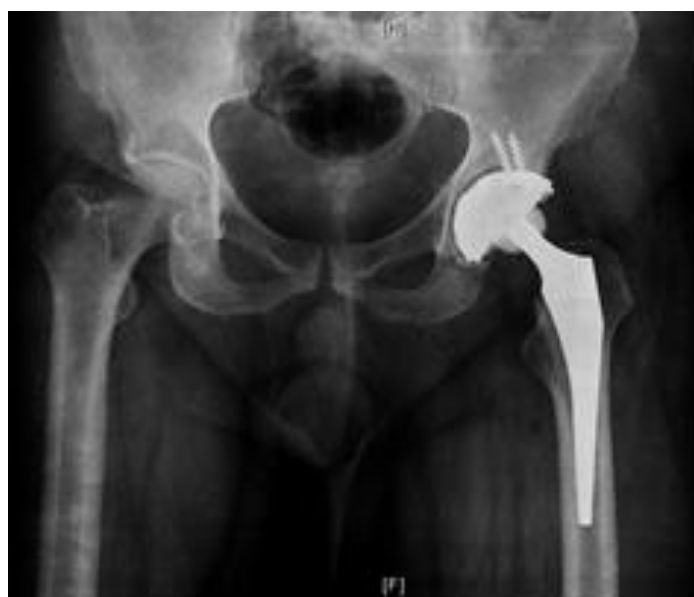

Post op 


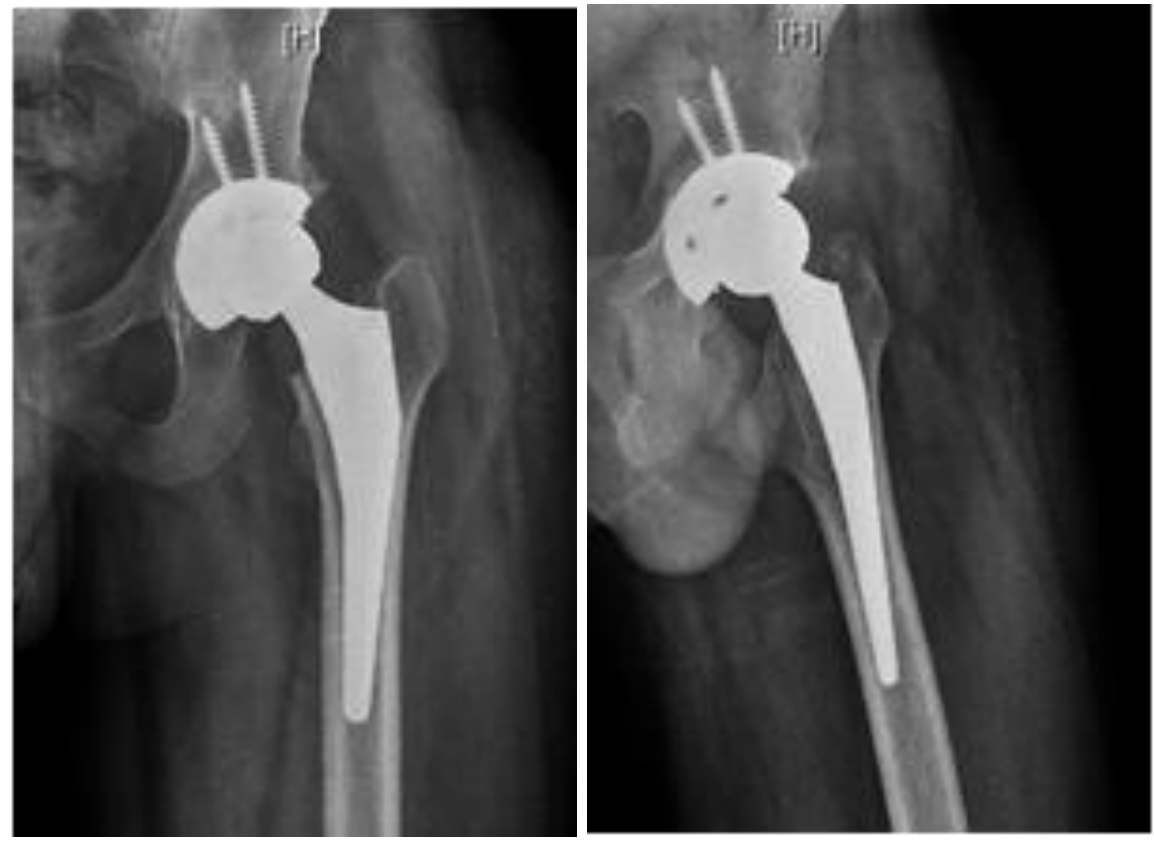

Last follow up

Case 12:- 48/ M Osteo Arthritis of Right Hip

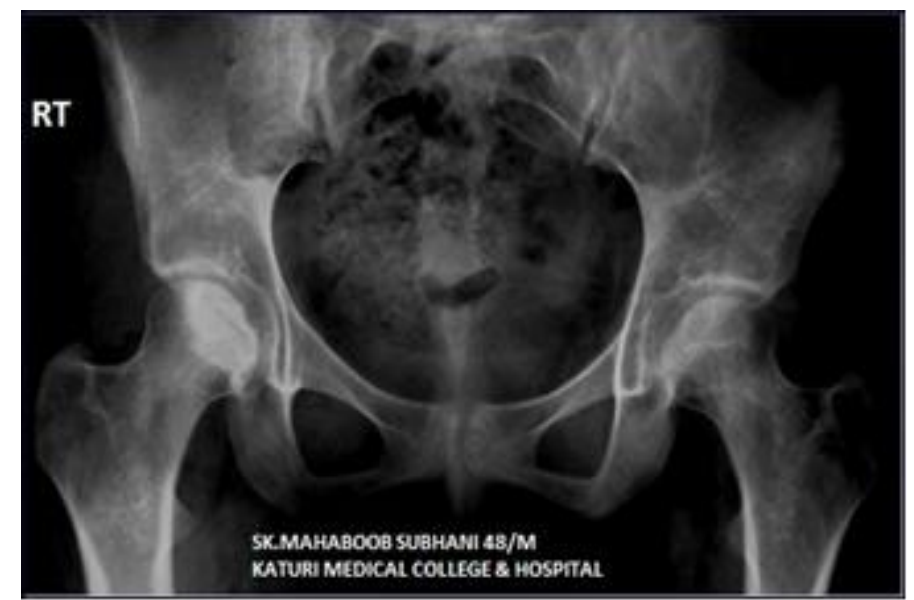

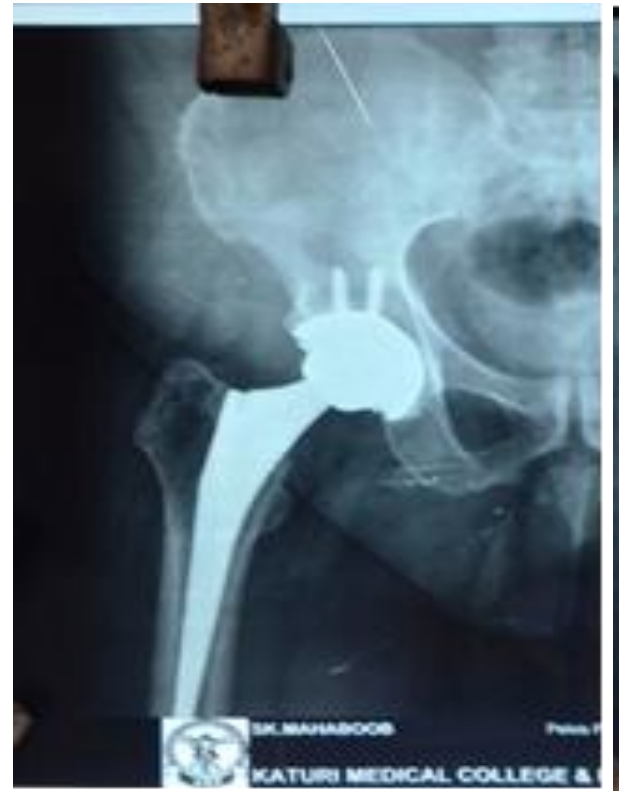

Pre Op

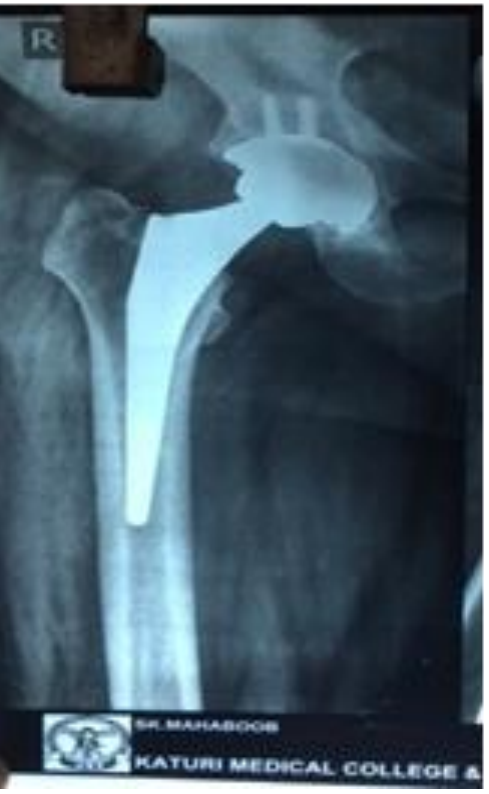

Post Op

Last Follow Up 


\section{Complications}

We have experienced few significant complications in our short follow up. 1 case of infection were identified. It was fortunately superficial infections, which responded well to intravenous antibiotics based on culture and sensitivity. The patient had good end result. One of them had moderate pain even at end of 1 year follow up. The culture organism was staphylococcus aureus.

There was a case of limb length discrepancy of $1.5 \mathrm{~cm}$ post operatively. However, patient had a good result functionally and negligible limp.

The worst of all complications is dislocation which occurred at 4 weeks after THR. The incident occurred when patient had dash board injury in a road traffic accident. Closed reduction could be achieved within 6 hours. He received strict bed rest for 4 weeks with lower limbs placed in abduction. He has received aggressive physiotherapy later and had good result at end of one year.

\section{Discussion}

Total hip replacement is considered one of the most important and successful intervention in the recent era. since total hip replacement was introduced, there has been a steady improvement in the technology associated with it, leading to better functional outcome and implant survivorship. The development of circumferentially coated uncemented implants which allow bone to grow in to or on to the prosthesis has led to improved implant survival rate and supports their growing use. The advantages of cementless femoral components include a reduced risk of cement-related cardiovascular and thromboembolic complications, the possibility of biological fixation, the minimisation of stress shielding of the proximal femur and potential of extended implant survival ${ }^{[7-11]}$

THA remains the treatment standard for collapsed osteonecrotic lesions. Patients with severe osteonecrosis requiring total hip arthroplasty are younger than those with other diseases; the risk of implant failure is higher. The peak incidence is in fourth decade, and overall there is a male preponderance ${ }^{[50]}$.

Some advocate that the specific pathologic process of osteonecrosis may predispose to an inferior outcome and several studies have shown suboptimal THA results in patients with osteonecrosis compared with similarly aged patients with osteoarthritis. Recent studies have demonstrated excellent outcomes with the use of improved cementing techniques and contemporary uncemented components. Seyler TM et al have compared around 23 studies between 1989 and 2004 and have found success rates varying from 52\% to $98 \%$
[50, 51]. Ours is a prospective study comprising of 32 patients with 32 uncemented total hip arthroplasties. Of the 32 cases included in the study majority are male patients. 22 patients are male constituting $68.75 \%$ of cases and the rest 10 are female patients constituting $31.25 \%$ of the cases

Male preponderance of osteonecrosis has been noticed in our study which was similar to most other studies. The mean age of patients in the group is 48.31 yrs (range 32 to 60 years), which is comparable to the study done by KimYH et al ${ }^{\text {[40] }}$ who reported the results in 98 patients mean age of $47.3 \mathrm{yrs}$ and with Rahman WA et al ${ }^{[52]}$ study who reported 31 patients with mean age of 47 . Garino and Steinberg ${ }^{[28]}$ studied 85 patients with an average age of 45 years.

\section{Mean Age of Patients Compared To Other Studies}

\begin{tabular}{|c|c|}
\hline STUDY & $\mathbf{4 8 . 3 1}$ \\
\hline KimYH et al & 47.3 \\
\hline Rahman WA et al & 47 \\
\hline Garino and steinberg & 45 \\
\hline
\end{tabular}

The average pre operative Harris Hip score in our study is 44.69 which are similar to the pre operative average Harris hip score in the studies done by Garino and Steinberg [28]. They studied 123 total hip arthroplasties with average Harris Hip Score of 45. Chiu KH et al ${ }^{[26]}$ studied 36 patients of osteonecrosis of femoral head with average Harris Hip Score of 36.8. In our study, the average pre operative Harris Hip Score of 44.69 improved to 84.2 at the end of 12 months follow up. The post op Harris Hip Score observed in our study is comparable to that in the study conducted by Garino and Steinberg ${ }^{[28]}$ who reported increase in the Harris Hip Score from 45 to 92 . It is also comparable to the study of Chiu $\mathrm{KH}$ et al ${ }^{[26]}$ who reported improvement from 36.8 to 83.5. Though Chiu et al study group had patients with worse preoperative score than our study group the end result was similar. This result shows that total hip replacement is effective even in case of worse pre-operative status of the patients.

\section{HHS Compared To Other Studies}

\begin{tabular}{|c|c|}
\hline PRE OPERATIVE & POST OPERATIVE \\
\hline STUDY 44.69 & 84.2 \\
\hline Garino and Steinberg 45 & 92 \\
\hline Chiu KH et al 36.8 & 83.5 \\
\hline
\end{tabular}

\section{Comparison with other studies}

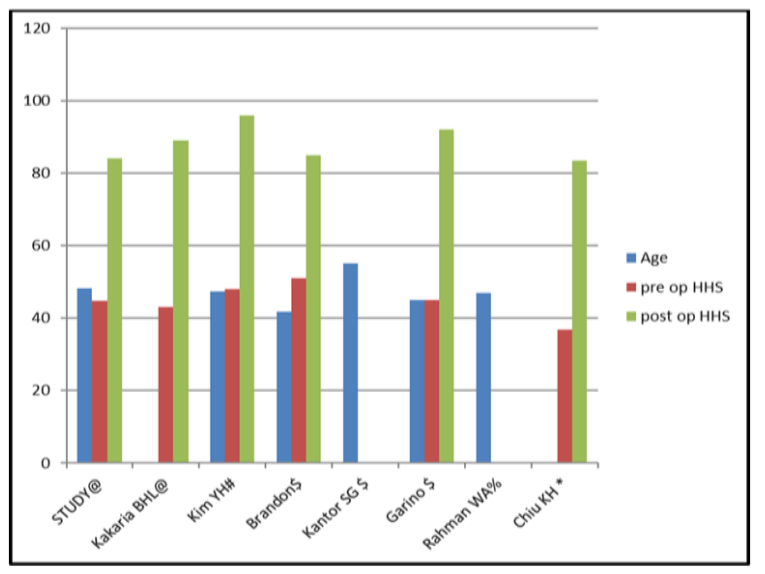

@ India, \# South Korea, \$ USA, \% Canada, * Hongkong. 


\section{Conclusion}

Uncemented replacement of the hip as a primary procedure can give a good clinical result which is comparable with the totally cemented joint. Although in some patients there are minor residual symptoms which do not limit activity. Although the operation can often be

performed more rapidly, it requires a high standard of bone preparation and in the attempt to produce a tight interference fit..On the acetabular side there is a positive gain in the augmentation of pelvic bone stock. with or without grafting, and. in most systems. failure on the acetabular side is uncommon. On the femoral side there appear to be both theoretical and practical advantages in methods of enhanced fixation. This study has shown that the outcome of uncemented total hip arthroplasty has excellent results in terms of pain relief, increased walking distance, and functional capabilities in patients.. Patients are satisfied with the results and most of them resumed their normal activities and are pursuing their jobs. Patient had significant improvement in range of motion at hip. Complications encountered in our short term follow up did not affect the outcome at the end. Neither the complications like aseptic loosening and wear requiring revision have not been found in our study, nor analysis regarding survivorship and longevity of the arthroplasty have been dealt with. Long term follow up is mandatory to analyze these aspects.

Our study supports the usage of uncemented THR in osteoarthritis in both young and elderly. The current trend, research and advent of new implants support uncemented THR in patients suffering from this crippling hip arthritis and avascular necrosis.

\section{Summary}

Our study is a prospective study of clinical and radiological analysis of uncemented total hip arthroplasties performed for various hip disorders

Study was carried out in Orthopaedics Department of katuri medical college and Hospital, chinakondrupadu, guntur from June 2015 to November 2016.

32 patients who underwent uncemented total hip replacement were included in the study

The age ranges from 32-60 years with mean age of 48.31years.

Most of the cases are between the age group of 51 to 60 years

- 22 patients are male and the rest 10 are female patients

- Right hip was involved in 12 cases and Left hip was involved in 20 cases

- Idiopathic osteonecrosis was most common etiology accounting for $50 \%$ of cases

- Average improvement of Harris hip score was 39.53 with a wide range of 22-57

- The result was excellent in 9 patients, Good in 17 patients, fair in 6 patients

- Mean HHS at each follow up visit was compared with pre-operative HHS using Paired T test and $p$ values were calculated. $\mathrm{P}$ value was found to be significant with each comparison.

\section{Financial Support and Sponsorship Nil}

\section{Conflicts of Interest}

There are no conflicts of interest

\section{References}

1. Buckwalter JA, Saltzman C, Brown T. The impact of osteoarthritis: Implications for research. Clin Orthop Relat Res. 2004; 427:6-15.

2. Cicuttini FM, Baker JR, Spector TD. The association of obesity with osteoarthritis of the hand and knee in women: A twin study. J Rheumatol. 1996; 23:1221-6.

3. Spector TD, Cicuttini F, Baker J, Loughlin J, Hart D. Genetic influences on osteoarthritis in women: A twin study. BMJ. 1996; 312:940-3.

4. Boles CA, el-Khoury GY. Slipped capital femoral epiphysis. Radiographics. 1997; 17:809-23.

5. Goodman DA, Feighan JE, Smith AD, Latimer B, Buly RL, Cooperman DR. Subclinical slipped capital femoral epiphysis. Relationship to osteoarthrosis of the hip. J Bone Joint Surg Am. 1997; 79:1489-97.

6. Bombelli R. The biomechanics of the normal and dysplastic hip. Chir Organi Mov. 1997; 82:117-27

7. Tryba M, Linde I, Voshage G, Zenz M. Histamine release and cardiovascular reactions to implantation of bone cement during total hip replacement. Anaesthesist. 1991; 40:25-32

8. Donaldson AJ, Thomson HE, Harper NJ, Kenny NW. Bone cement implantation syndrome. Br J Anaesth. 2009; 102:12-22.

9. Borghi B, Casati A. Thromboembolic complications after total hip replacement. Int Orthop. 2002; 26:44-47.

10. Ereth MH, Weber JG, Abel MD et al. Cemented versus noncemented total hip arthroplasty: embolism, hemodynamics, and intrapulmonary shunting. Mayo Clinic Proc. 1992; 67:1066-1074.

11. Chandran P, Azzabi M, Andrews M, Bradley JG. Periprosthetic bone remodelling after 12 years differs in cemented and uncemented hip arthroplasties. Clin Orthop Relat Res. 2012; 470:1431-1435.

12. Harkess JW, Crockarell JR. Arthroplasty of hip. In: Canale ST, Beaty JH. editors Campbell's Operative Orthopaedics. 11th ed. Mosby Elsevier. 2008; 7:314-315.

13. Callaghan JJ, Albright JC, Goetz DD et al. Charnley total hip arthroplasty with cement. Minimum twenty-five-year follow up. JBJS (Am). 2000; 82:487-97.

14. Learmonth ID, Young C, Rorabeck C. The operation of the century: total hip replacement. Lancet. 2007; 370: 1508-1519.

15. Brown SR, Davies WA De, Heer DH, Swanson AB. Long-term survival of Mckee- Farrar total hip prosthesis. Clin Orthop Relat Res. 2002; 402:157-63.

16. Charnley J. Arthroplasty of the hip: a new operation. Lancet. 1961; 1:1129-32.

17. Hartley W, Mc Auley JP, Culpepper WJ, Engh CA JR, Engh CA Sr: Osteonecrosis of Femoral Head Treated with Cementless THA. Investigation performed at the Anderson Orthopaedic Research Institute, Alexandria, Virginia. JBJS. 2000; 82(10):1408-1413

18. Kim YH, Oh SH, Kim JS, Koo KH. Contemporary Total Hip Arthroplasty with and without Cement in Patients with Osteonecrosis of Femoral Head. JBJS (Am). 2003; 85:675-681

19. Cebesoy O, Erdemli B, Kose KC, Guzel B, Cetin I. Mid Term Results of Total Hip Replacement in Osteonecrosis of the Hip Joint. Acta Orthop Traumatol Turc. 2006; 40 (4):301-306 47.

20. Kantor SG, Huo MH, Huk OL, Salvati EA. Cemented total hip arthroplasty in patients with osteonecrosis. A 6 year minimum follow up study of second generation 
cement techniques. The Journal of Arthroplasty. 1996; 11(3):267-271.

21. Kantor SG, Huo MH, Huk OL, Salvati EA. Cemented total hip arthroplasty in patients with osteonecrosis. A 6 year minimum follow up study of second generation cement techniques. The Journal of Arthroplasty. 1996; 11(3): 267-271.

22. Christophe N, Courpied JP, Kerboull M, Michel Postel, Hamadouche M. Charnley Kerboull Total Hip Arthroplasty for Osteonecrosis of the femoral head.A minimal 10 year follow up study. The Journal of Arthroplasty. 2006; 21(4):533-40.

23. Mont MA, Jones LC, Hungerford D. Non traumatic osteonecrosis of femoral head-Ten Years Later. JBJS (Am). 2006; 88(5):1117-1132.

24. Mont MA, Seyler TM, Plate JF, Delanois RE, Parvizi J. Uncemented THR in young adults with osteonecrosis of femoral head. A Comparitive study. JBJS (Am). 2006: 88(3):104-109

25. Yuan BS, Taunton MJ, Trousdale RT. Total Hip arthroplasty for Alcoholic Osteonecrosis of the Femoral Head.; Orthopaedics. 2009; 32(6):400.

26. Hungerford DS. Treatment of Osteonecrosis of the Femoral Head. Everything's New. The Journal of Arthroplasty. 2007 22(4):91-94.

27. Chiu Kh, Shen WY, Ko CK, Chan KM. Osteonecrosis of the femoral head treated with cemented THA. A comparison with other diagnoses. The Journal of Arthroplasty, 1997; 112(6):683-688

28. Xenakis TA, Beris AE, Malizos KK et al. Total Hip Arthroplasty for Avascular necrosis and Degenerative osteoarthritis of the hip. Clin Orthop Relat Res. 1997; 341:62-68

29. Garino JP, Steinberg ME. Total Hip Arthroplasty in Patients with Avascular Necrosis of Femoral Head: Clinical orthopaedics and related research. 1997; 334:108-115.

30. Crock HV. An atlas of the arterial supply of the head and neck of the femur in man. Clin Orthop. 1980; 152:17-27.

31. Weitbrecht J. Syndesmologia sive Historia. Ligamentorum Corporis, Humani guain, Seeundum. Observationes Anatomicas Concinnavit et Figuris ad Objecta Reentia Adumbratis Illustravit. Petropoli Typogr Acad Sci.1742; 139-141.

32. Leighton RK. Fractures of the Neck of the Femur. In: Rockwood and Green's fracture in Adults. Ed: Bucholz RW, Heckman JD, Court-Brown CM. $6^{\text {th }}$ Ed Philadelphia, Lippincott Williams \& Wilkins. 2006; 1753-1791.

33. Chung SMK. The arterial supply of the developing proximal end of the human femur. J Bone Joint Surg (Am) 1976; 58:961-965.

34. Claffey TJ. Avascular necrosis of the femoral head: an anatomical study. J Bone Joint Surg Br. 1960; 42:802809.

35. Howe JWW, Lacey IT, Schwartz RP. A study of the gross anatomy of the arteries supplying the proximal portion of the femur and the acetabulum. 1950; 32:856865

36. McLeish RD, Charnley J, Abduction Forces in the One Legged Stance. J Biomech. 1970; 3(2):191-209.

37. Andriarcchi TP, Anderson GB, fermier RW, Stern D et al. A study of Lower Limb Mechanics during Stair Climbing. JBJS. 1980; 62:749-757

38. Harkess JW, Crockarell JR. Arthroplasty of hip. In:
Canale ST \& Beaty JH editors Campbell's Operative Orthopaedics. 11th ed. Mosby Elsevier; 2008; 7:314-315

39. Capello WN D, Antonio JA, Feinberg JR, Manely MT. Hydroxyapatite - Coated total hip components in patients less than 50 years old. Clinical and Radiographic Results after Five To Eight Years of Follow Up. JBJS 1997; 79: 1023-1029

40. Ya kup Ekmekci et al: Thrombophilia and AVN of Femoral Head in Kidney Allograft Recipients: Nephrol Dial Transplant. 2006; 21:3555 - 3558.

41. Kim YH, Oh SH, Kim JS, Koo KH. Contemporary Total Hip Arthroplasty with and without Cement in Patients with Osteonecrosis of Femoral Head. JBJS (Am). 2003; 85:675-681

42. Devan PA, Robinson EJ, Bourne RB et al. Measurement of polyethylene wear in acetabular components inserted with or without cement: JBJS 1997; 79: 682-689.

43. Callaghan JJ, Gaffey LJ et al Cementless acetabular fixation at fifteen years. JBJS (Am) 2004; 86: 257-261

44. Schmalzrid TP, Callaghan JJ. Current Concepts Review in Total Hip and Knee Replacements. JBJS 1999; 81:115136.

45. Xenakis TA, Beris AE, Malizos KK et al. Total Hip Arthroplasty for Avascular necrosis and Degenerative osteoarthritis of the hip. Clin Orthop Relat Res 1997; 341:62-68.

46. Beaule PE, Amstutz HC. Management of Ficat Stage III and IV Osteonecrosis of the Hip. J Am Acad Orthop Surg 2004; 12 (2):96-105.

47. Engh CA, Bobyn JD, Glassman AH. Porous-coated hip replacement. The factors governing bone ingrowth, stress shielding, and clinical results J Bone Joint Surg Br. 1987; 69(1):45-55.

48. Kristian Bjørgul, Wendy M Novicoff, ST Andersen, K Brevig, F Thu, M Wiig et al. No differences in outcomes between cemented and uncemented acetabular components after 12-14 years: results from a randomized controlled trial comparing Duraloc with Charnley cups. J Orthopaed Traumatol. 2010 11:37-45.

49. Weiss RJ, Hailer NP, Stark A, Karrholm J. Survival of uncemented acetabular monoblock cups: evaluation of 210 hips in the Swedish Hip Arthroplasty Register. Acta Orthop. 2012; 83:214-9.

50. Eskelinen A, Remes V, Helenius I et al. Total hip arthroplasty for primary osteoarthrosis in younger patients in the Finnish arthroplasty register. 4,661 primary replacements followed for 0-22 years. Acta Orthop. 2005; 76:28-41.

51. Hamilton TW, Goodman SM, Figgie M. SAS Weekly Rounds: Avascular Necrosis. HSSJ. 2009; 5:99-113.

52. Seyler TM, Cui Q, Mihalko WM, Mont MA, Saleh KJ. Advances in hip arthroplasty in the treatment of osteonecrosis. Instructional Course Lecture. 2007; 56:221-233.

53. Rahman WA et al. Total Hip arthroplasty in steroid induced osteonecrosis: early functional and radiological outcomes. Canada Journal of Surgery. 2012; 1:55(5). DOI: $10.1503 /$ cjs.032510. 